\title{
30-day readmission rate and its causes in general surgical patients
}

\author{
Rizwan Sultan \\ Aga Khan University, Rizwan.sultan@aku.edu \\ Umme Hani Abdullah \\ Aga Khan University \\ Tabish Chawla \\ Aga Khan University, tabish.chawla@aku.edu
}

Follow this and additional works at: https://ecommons.aku.edu/pakistan_fhs_mc_surg_gen

Part of the Surgery Commons

\section{Recommended Citation}

Sultan, R., Abdullah, U. H., Chawla, T. (2018). 30-day readmission rate and its causes in general surgical patients. Journal of the College of Physicians and Surgeons Pakistan, 28(4), 314-316.

Available at: https://ecommons.aku.edu/pakistan_fhs_mc_surg_gen/60 


\title{
30-Day Readmission Rate and its Causes in General Surgical Patients
}

\author{
Rizwan Sultan1, Umme Hani Abdullah² and Tabish Chawla1
}

\begin{abstract}
Objective: To find out the 30-day readmission rate for different surgical procedures and determine the causes for readmissions.

Study Design: An audit report.

Place and Duration of Study: Department of Surgery, The Aga Khan University Hospital, Karachi, in the calendar year 2014. Methodology: Records were retrospectively reviewed for 30-day readmission rate and their cause in general surgical patients who underwent a general surgical procedure at The Aga Khan University Hospital, Karachi, in the year 2014.

Results: Out of $217(6.4 \%)$ readmissions in 3,387 patients, more than $50 \%$ unplanned readmissions were avoidable. The highest readmission rate was after placement of feeding tubes $(28.5 \%)$.

Conclusion: More than half of the readmissions could have been prevented by proper patient/attendant education, good communication and provision of nursing services to these patients beyond the hospital.
\end{abstract}

Key Words: Surgery patients. Readmission rate. Causes of readmission. Tertiary care centre.

\section{INTRODUCTION}

Whether planned or unplanned, readmission in a hospital is an additional financial, social and psychological burden to both patient as well as family. It is also a quality indicator for hospital in NHS, and contributes to "star" status for a hospital. From 2003 to 2004, 19.5\% of all medicare beneficiaries, who were discharged from a hospital, were readmitted within 30 days, leading to a cost of $\$ 17.4$ billion. ${ }^{1}$ It was estimated that a single readmission after pancreatic resection costs an average of $\$ 16,000$ or more. ${ }^{1}$ Readmission problem is different in surgical patients compared with medical patients. ${ }^{2,3} \mathrm{After}$ a surgical procedure, majority $(70.5 \%)$ of readmissions are due to medical conditions and are unavoidable. Among the medicare beneficiaries undergoing major bowel surgery, $16.6 \%$ were readmitted for gastrointestinal problems, and $6.4 \%$ were readmitted with a postoperative infection. 4

In developing countries like Pakistan, where there is a marked shortage of nursing care outside hospitals, 5 risk of readmission with minor ailments increases significantly. 6 Similarly, readmission rate seems also related to the education of the caretakers about the disease. 7,8 Besides cost of treatment, avoidable readmissions also burdens emergency departments of

1 Department of Surgery, The Aga Khan University Hospital, Karachi.

2 Medical Student, The Aga Khan University Hospital, Karachi. Correspondence: Dr. Rizwan Sultan, Fellow Trauma and Surgery, Department of Surgery, The Aga Khan University Hospital, Stadium Road, Karachi.

E-mail: imrizwan12@yahoo.com

Received: November 29, 2016; Accepted: January 10, 2018. hospitals with preventable admissions. ${ }^{9}$ Data regarding cost of readmissions after a surgical procedure is not available from Pakistan or South Asia.

Knowledge of causes of readmissions is important to be able to avoid the avoidable causes; and rate of readmission is important for preoperative counselling of patients and their families to decrease the anxiety and frustration associated with readmissions.

The objective of this study was to review all general surgical procedures performed in the year 2014 to find out procedure specific 30-day readmission rate and causes of these readmissions.

\section{METHODOLOGY}

Exemption from Ethical Review Committee of The Aga Khan University was taken prior to the start of study (3973-sur-ERC-15). The audit included all patients undergoing general surgical procedures in the year 2014 at Aga Khan Hospital, Karachi. The patients who left against medical advice or died during the index hospital admission were excluded from the study.

The investigators reviewed computer records of all patients for 30-day readmissions. Medical records of the patients with readmissions within 30 days of their discharge were then reviewed for cause of readmission; and details of the readmission were recorded on a predesigned proforma. The variables recorded were the cause of readmission, median days between discharge and readmission, whether readmission was planned or unplanned/avoidable or unavoidable, requirement of intervention in readmission, and eventual outcome.

Data was entered in SPSS 19. Continuous variables like age, length of stay, and time between primary discharge to readmission were measured by using mean $+/-$ SD or 
medians with IQR. The categorical variables were described in frequency with percentages. Comparison between the two groups was done using Chi-square test. P-value of $<0.05$ was considered significant.

\section{RESULTS}

The total number of procedures performed in the year 2014 in the Department of General Surgery at Aga Khan University Hospital, Karachi, was 3,428 (Table I). Mean age was $46.94 \pm 15.9$ years. Nineteen hundred and fiftyfour $(57 \%)$ patients were male. Median LOS (length of stay) was 2 days (IQR 1-4). Three thousand (87.5\%) procedures were performed under general anesthesia. Two thousand, seven hundred and fifty-one (80\%) procedures were done after admitting patient in the hospital; $2,451(71.5 \%)$ cases were electively planned before the day of surgery. There were 41 deaths among these patients (mortality rate $1.1 \%$ ), rest of 3,387 patients

Table I: Details of patients $(n=3,428)$ who underwent general surgical procedures at AKUH in the year 2014.

\begin{tabular}{l|c}
\hline Variables & Frequency \\
\hline Mean age & $46.94 \pm 15.9$ years \\
\hline Gender & $1954(57 \%)$ \\
Males & $1474(43 \%)$ \\
Females & 2 days (IQR 1-4) \\
\hline Median LOS & 60 minutes (IQR 35-92) \\
\hline Median length of surgery & $3000(87.5 \%)$ \\
\hline Type of anesthesia & $299(8.8 \%)$ \\
GA & $113(3.3 \%)$ \\
LA & $16(0.5 \%)$ \\
\hline Regional (spinal, caudal, epidural) & \\
\hline MAC (monitored anesthesia care) & $2718(79.3 \%)$ \\
\hline Nature of admission & $710(20.7 \%)$ \\
Inpatient & \\
Day care & $2451(71.5 \%)$ \\
\hline Nature of procedure & $759(22.1 \%)$ \\
Elective & $218(6.4 \%)$ \\
Emergency & \\
Add on & $41(1.2 \%)$ \\
\hline Outcome & $3387(98.8 \%)$ \\
Mortality &
\end{tabular}

Table II: Details of 30-day readmissions.

\begin{tabular}{l|c}
\hline Variables & Frequency \\
\hline Number of patients followed for 30-day re-admissions & 3387 \\
\hline Total re-admissions & $217(6.4 \%)$ \\
\hline Planned re-admissions & $32(14.9 \%)$ \\
\hline Duration between primary discharge and re-admission & $\begin{array}{c}\text { (median) } 15 \text { days } \\
\text { (IQR 3-23) }\end{array}$ \\
\hline Unplanned re-admissions & $185(85.1 \%)$ \\
\hline Unplanned unavoidable re-admissions & $91(49 \%)$ \\
\hline Duration between primary discharge and re-admission & $\begin{array}{c}\text { (median) } 8 \text { days } \\
\text { (IQR 3-17) }\end{array}$ \\
\hline Unplanned avoidable re-admissions & $94(51 \%)$ \\
\hline Duration between primary discharge and re-admission & (median) 3 days \\
\hline Second intervention required & $($ IQR $1-7)$ \\
\hline Mortality & $15(0.44 \%)$ \\
\hline & $4(0.12 \%)$ \\
\hline
\end{tabular}

were discharged from hospital. Out of these, 209 $(6.17 \%)$ patients were readmitted within 30 days of their discharge. Eight patients required more than one readmission within 30 days making, a total of 217 readmissions $(6.4 \%)$.

Out of 217 admissions, 32 admissions were planned at the time of discharge and were not avoidable (Table II). Rest of 185 readmissions were unplanned. Ninety-four unplanned admissions were due to minor issues like increased ileostomy output, postoperative pain, nausea, vomiting, urinary retention or surgical wound related issues. These were managed in emergency room and did not require any further interventions; while 91 patients were admitted in the hospital and 15 required another intervention for a postoperative complication. Seventy-six patients had a medical issue like electrolyte imbalance, kidney injury or pneumonia, which did not require any intervention. Out of 15 patients requiring surgical intervention in the readmission, there was no mortality; but out of 76 who were conservatively treated, there were four mortalities.

Procedure-wise readmission rate (Table II) showed that the patients operated for placement of feeding tubes had highest 30 -day readmission rate of $28.57 \%$. After major abdominal surgeries like Whipples procedure and Ivor Lewis Esophagectomy, the 30 -day readmission rate was $21.74 \%$ and $14.28 \%$, respectively. Stoma formation in lower GI surgery was associated with readmission rate of $15.7 \%$ at the time of primary procedure and an additional $10.5 \%$ readmission rate after stoma closure; while lower GI surgery without stoma was associated

Table III: Procedure-wise readmission rate.

\begin{tabular}{l|c|c|c|c}
\hline Procedure & $\begin{array}{c}\text { Total } \\
\text { patients }\end{array}$ & Readmission & $\begin{array}{c}\text { No } \\
\text { readmission }\end{array}$ & $\begin{array}{c}\text { Procedure } \\
\text { specific } \\
\text { readmission } \\
\text { rate }\end{array}$ \\
\hline Hernia & 326 & 25 & 301 & $7.67 \%$ \\
\hline $\begin{array}{l}\text { Wound debridement and } \\
\text { amputations }\end{array}$ & 173 & 14 & 159 & $8.1 \%$ \\
\hline Skin and subcutaneous tissues & 490 & 20 & 470 & $4.08 \%$ \\
\hline Anal and perianal procedures & 374 & 17 & 357 & $4.54 \%$ \\
\hline Diagnostic lap & 47 & 6 & 41 & $12.76 \%$ \\
\hline Endoscopic procedures & 40 & 2 & 38 & $5 \%$ \\
\hline Appendectomy & 167 & 10 & 157 & $5.99 \%$ \\
\hline Cholecystectomy & 1033 & 37 & 996 & $3.58 \%$ \\
\hline Splenectomy & 14 & 1 & 13 & $7.14 \%$ \\
\hline Feeding tubes & 63 & 18 & 45 & $28.57 \%$ \\
\hline Bile duct and liver & 32 & 1 & 31 & $3.125 \%$ \\
\hline Gastric procedures & 60 & 3 & 57 & $5 \%$ \\
\hline Whipple & 23 & 5 & 18 & $21.74 \%$ \\
\hline Two-stage esophagectomy & 21 & 3 & 18 & $14.28 \%$ \\
\hline Abdominal mass & 19 & 3 & 16 & $15.79 \%$ \\
\hline Pancreatic procedures & 6 & 0 & 6 & $0 \%$ \\
\hline Lower Gl surgery with stoma & 140 & 22 & 118 & $15.71 \%$ \\
\hline Lower Gl surgery without stoma & 95 & 6 & 89 & $6.32 \%$ \\
\hline Stoma closure & 86 & 9 & 77 & $10.5 \%$ \\
\hline Other Laparotomy & 178 & 15 & 163 & $8.43 \%$ \\
\hline Total & 3387 & 217 & 3170 & $6.40 \%$ \\
\hline & & & & \\
\hline
\end{tabular}


with readmission rate of $6.32 \%$. This difference between the two groups was statistically significant $(p=0.029)$.

\section{DISCUSSION}

This study showed that 30-day readmission rate after discharge was $6.4 \%$ in general surgery department of the Aga Khan University Hospital, Karachi. More than $50 \%$ of unplanned admissions were for minor issues and were avoidable with good communication and education at discharge and better involvement of nursing staff outside the hospital (home healthcare). It would have helped in reduction of overall cost of the treatment as well as burden on the Emergency Department of the hospital.

The highest readmission rate was associated with placement of feeding tubes. There are two reasons for these readmissions. Most of these patients with malignancy were planned for chemotherapy and some are elderly people with multiple comorbids requiring readmission due to medical issues. Every 5th and 7th patient gets readmitted after major abdominal procedures like Whipples procedure and Ivor Lewis Esophagectomy. Another interesting finding was, readmission rate in lower GI surgery patient with stoma, which was 2.5 times the readmission rate in patients without stoma. The patients with stoma had to bear another $10.5 \%$ readmission rate at the time of stoma reversal surgery.

There is very little data on readmission rate and its causes after discharge from surgery department. In 2007, Dayo et al. suggested that the readmissions cannot be predicted on the basis of age, comorbidities, psychiatric illness and number of drugs on discharge. 10 In 2011, Atul Gawande suggested that if we target the patients who are at high risk for readmissions, we can certainly decrease number of readmissions and save cost. ${ }^{11}$ These patients were labelled as "hot spots". In 2012, Kassin et al. concluded that multiple comorbids, inpatient surgical procedures and need of admission before surgery were risk factors for readmission. ${ }^{12}$ Intraabdominal procedures were prone with more readmission rate requiring more vigilance and attention. ${ }^{13}$ Less educated family and poor socioeconomic background are also found to be significantly associated with the readmission rate. ${ }^{14}$ Similarly, stoma formation is also associated with higher postoperative readmission rate. ${ }^{15}$

To the best of authors' knowledge, this is a first study looking at readmission rate and causes of readmissions in Pakistan. Large number of patients, variety of surgical procedures, and utilization of computerized data for retrieval of readmissions were our advantages; while we could have missed the patients not readmitted in the hospital. The authors have introduced concept of hotline, in which a cellular phone carried by a registered nurse is given to the patient at discharge so that he/she can contact her regarding any complaint at home to decrease the unplanned avoidable readmission rate.

\section{CONCLUSION}

Effective communication using hotline, patient education and use of home healthcare services can decrease unplanned avoidable admission rate. In some high risk procedures, the risk of readmission should be explained to the patients preoperatively.

\section{REFERENCES}

1. Kent TS, Sachs TE, Callery MP, Vollmer CM. Readmission after major pancreatic resection: a necessary evil? J Am Coll Surg 213:515-23.

2. Khuri SF, Henderson WG, De Palma RG, Mosca C, Healey NA, Kumbhani DJ. Determinants of long-term survival after major surgery and the adverse effect of postoperative complications. Ann Surg. 2005; 242:326-43.

3. Anderson GF, Steinberg EP. Hospital readmissions in the medicare population. N Engl J Med 1984; 311:1349-53.

4. Jencks SF, Williams MV, Coleman EA. Rehospitalizations among patients in the medicare fee-for-service program. N Engl J Med 2009; 360:1418-28.

5. Khowaja K. Healthcare systems and care delivery in Pakistan. J Nurs Adm 2009; 39:263-5.

6. Hayden DM, Pinzon MCM, Francescatti AB, Edquist SC, Malczewski MR, Jolley JM, et al. Hospital readmission for fluid and electrolyte abnormalities following ileostomy construction: preventable or unpredictable? J Gastrointest Surg 2013; 17: 298-303.

7. Healy SJ, Black D, Harris C, Lorenz A, Dungan KM. Inpatient diabetes education is associated with less frequent hospital readmission among patients with poor glycemic control. Diabetes Care 36:2960-7.

8. Marcantonio ER, McKean S, Goldfinger M, Kleefield S, Yurkofsky M, Brennan TA. Factors associated with unplanned hospital readmission among patients 65 years of age and older in a medicare managed care plan. Am J Med 1999; 107:13-7.

9. Mahmoudi S, Taghipour HR, Javadzadeh HR, Ghane MR, Goodarzi H, Motamedi MHK. Hospital readmission through the emergency department. Trauma Mon 2016; 21:e35139.

10. Adeyemo D, Radley S. Unplanned general surgical readmissions - how many, which patients and why? Ann $R$ Coll Surg Engl 2007; 89:363-7.

11. Gawande A. The hot spotters: can we lower medical costs by giving the neediest patients better care? New Yorker 2011:40-51.

12. Kassin MT, Owen RM, Perez SD, Leeds I, Cox JC, Schnier K, et al. Risk factors for 30-day hospital readmission among general surgery patients. J Am Coll Surg Sep; 215:322-30.

13. Aust JB, Henderson W, Khuri S, Page CP. The impact of operative complexity on patient risk factors. Ann Surg 2005; 241:1024-7.

14. Hendren S, Morris AM, Zhang W, Dimick J. Early discharge and hospital readmission after colectomy for cancer. Dis Colon Rectum 2011; 54:1362-7.

15. Guinier D, Mantion GA, Alves A. Risk factors of unplanned readmission after colorectal surgery: a prospective, multicenter study. Dis Colon Rectum 2007; 50:1316-23.

$$
\text { .......... }
$$

